\title{
ANALISIS DINAMIS MODEL MATEMATIKA PERTUMBUHAN JUMLAH MAHASISWA PROGRAM STUDI PENDIDIKAN MATEMATIKA STKIP PGRI PASURUAN
}

\author{
Wahyuni Ningsih', Rif'atul Khusniah ${ }^{2}$ \\ STKIP PGRI Pasuruan, wahyuni_ningsih@ stkippgri-pasuruan.ac.id ${ }^{1}$ \\ STKIP PGRI Pasuruan, rifatulkhusniah@stkippgri-pasuruan.ac.id ${ }^{2}$ \\ Received : 6 September 2018, Revised : 6 Oktober 2018, Accepted : 17 Oktober 2018 \\ (C) Mathematics Education Unugiri 2018
}

\begin{abstract}
Mathematical Models of population growth on the number of students, especially in the mathematics education program STKIP PGRI Pasuruan has been obtained. One of the purposes of this modeling was to find out the behavior of the model or system. To determine the behavior of the systems can be used dynamic analysis of the model. Therefore, a dynamic analysis of the growth model in the number of students, especially in the mathematics education program STKIP PGRI Pasuruan has been done in this article. The dynamic analysis that is used in this article is about a stability analysis around the equilibrium point of the model. Completion of the model using the Runge-Kutta method was simulated so that obtained a graphical completion of the model. Analytical and graphical systems stability analysis showed that the system was asymptotically unstable.
\end{abstract}

Keywords : dynamic analysis, equilibrium point, Runge-Kutta method, stability

\begin{abstract}
Abstrak
Model matematika pertumbuhan populasi pada jumlah mahasiswa, khususnya di program studi pendidikan matematika STKIP PGRI Pasuruan sudah didapatkan. Salah satu tujuan dilakukan pemodelan ini adalah untuk mengetahui perilaku dari model atau sistem. Untuk mengetahui perilaku sistem dapat digunakan analisis dinamis terhadap model. Oleh karena itu, pada artikel ini dilakukan analisisdinamis terhadap model pertumbuhan jumlah mahasiswa program studi pendidikan matematika STKIP PGRI Pasuruan. Analisis dinamis yang digunakan pada artikel ini berupa analisis kestabilan sistem di sekitar titik setimbang model. Penyelesaian model menggunakan metode RungeKutta yang di simulasikan sehingga diperoleh bentuk penyelesaian model secara grafik. Analisis kestabilan sistem secaraanalitikdan grafik menunjukkan bahwa sistem tidak stabil asimtotik.
\end{abstract}

Kata kunci : analisis dinamis, kestabilan, metode Runge-Kutta, titik setimbang

\section{Pendahuluan}

Pada awal tahun 1970, sistem dinamis tengah menjadi suatu pengetahuan dan metode penelitian pada sistem dinamis manusia yang rumit. [2]. Sistem dinamis tidak hanya memiliki perangkat pemodelan yang lengkap, tapi juga model berfikir dan metodologi yang lengkap[3]. Metode ini sesuai untuk memperlakukan permasalahan siklis dan jangka panjang, serta diaplikasikan untuk mempelajari masalah sosial ekonomi yang memiliki data yang cukup dan teliti.[3]. Pada penelitian Ying [3], sistem dinamis telah menjadi metode penelitian utama yang dikombinasikan dengan multi disiplin ilmu lain seperti ekonomi, statistika, untuk menganalisa simulasi model matematika sistem pariwisata.

Penelitian yang dilakukan oleh Ningsih dan Khusniah [1] termasuk kedalam persamalahan sosial. Penelitiannya terhadap pertumbuhan jumlah mahasiswa program studi pendidikan matematika 
STKIP PGRI Pasuruan menghasilkan model matematika berupa sistem persamaan diferensial nonlinear time-invariant (autonomous).Model matematika yang dihasilkan tersebut ditunjukkan oleh (1).

$$
\begin{gathered}
\frac{d J(t)}{d t}=x_{0} J(t)+x_{1} B(t)+x_{2} F(t) ; \\
\frac{d B(t)}{d t}=y_{0} B(t)+y_{1} \frac{B^{2}(t)}{J(t)}+y_{3} \frac{B^{2}(t)}{F(t)} ; \\
\frac{d F(t)}{d t}=\left(z_{0}-\frac{1}{20}\right) F(t)+z_{2} \frac{F^{2}(t)}{J(t)}+z_{3} B(t) ;
\end{gathered}
$$

Variabel state dalam sistem tersebut adalah Jumlah mahasiswa baru program studi pendidikan matematika $J$, biaya kuliah $B$, dan fasilitas yang disediakan $F$.Kemudian parameter yang mempengaruhi yaitu tingkat pertumbuhan jumlah mahasiswa program studi pendidikan matematika $x_{0}$, tingkat konsumsi perkapita $x_{1}$ yang mempengaruhi variabel $J$, tingkat rasio permintaan dan pasokan fasilitas $x_{2}$ yang mempengaruhi variabel $J$, tingkat kenaikan/penurunan biaya kuliah $y_{0}$, tingkat konsumsi perkapita $y_{1}$ yang mempengaruhi variabel $B$, tingkat rasio jumlah fasilitas dan biaya kuliah $y_{3}$ yang mempengaruhi variabel $B$, tingkat penambahan/penurunan jumlah fasilitas $z_{0}$, tingkat rasio permintaan dan pasokan fasilitas $z_{2}$ yang mempengaruhi variabel $F$, dan tingkat rasio jumlah fasilitas dan biaya kuliah $z_{3}$ yang mempengaruhi variabel $F$. Serta $t$ adalah waktu.Hubungan ketiga variabel state tersebut dapat dilihat pada diagram skematik yang ditunjukkan oleh Gambar 1.

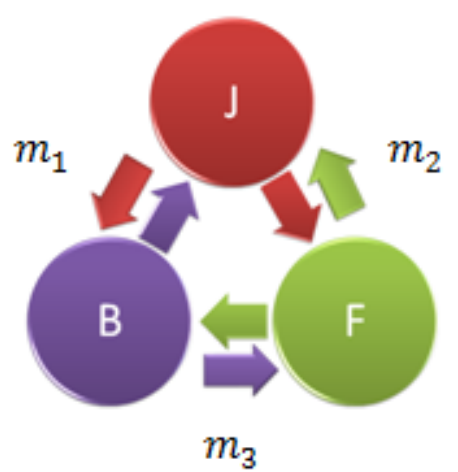

Gambar 1. Diagram Skematik [1].

dengan $m_{1}=\frac{B(t)}{J(t)} ; m_{2}=\frac{F(t)}{J(t)} ; m_{3}=\frac{B(t)}{F(t)}$.

Dalam pembentukan model tersebut, beberapa batasan masalah yang digunakan peneliti [1] diantaranya yaitu pada variabel $J$, jumlah mahasiswa yang dimaksud adalah jumlah mahasiswa baru tiap tahun ajaran baru. Dengan kata lain jumlah mahasiswa kumulatif tidak diperhatikan, mahasiswa yang keluar atau mahasiswa yang transfer juga tidak diperhatikan. Kemudian, variabel $B$ yang dimaksud adalah biaya yang dikeluarkan mahasiswa baru di tahun pertama perkuliahan (2 (dua) semester pertama). Sementara itu, variabel $F$ yang dimaksud adalah fasilitas yang disediakan perguruan tinggi dan dibatasi hanya pada fasilitas gedung ruang kelas yang digunakan mahasiswa saat perkuliahan.

Model matematika yang telah dihasilkan tersebut belum dilakukan analisis dinamis. Analisis ini berarti mencari suatu pemahaman yang mendalam dari suatu proses melalui penyelesaian sejumlah persamaan atau simulasi sederhana untuk suatu nilai input dan parameter tertentu [4]. Atau dapat dikatakan bahwa analisis ini berguna untuk mengetahui perilaku sistem melalui model matematika dari sistem tersebut. Oleh karena itu, pada artikel ini dilakukan analisis dinamis terhadap model (1) untuk mengetahui perilaku sistem tersebut.

\section{Metode Penelitian}

Metode Penelitian yang digunakan pada artikel ini adalah kajian pustaka. Kajian pustaka ini dilakukan dengan mengkaji model matematika yang ditunjukkan oleh sistem persamaan (1) melalui studi literatur. Kemudian metode analisis yang dilakukan yaitu analisis kestabilan disekitar titik setimbang sistem. Analisis kestabilan yang digunakan berupa kestabilan lokal. Hal ini dengan melakukan linearisasi sistem (1) terlebih dahulu sehingga teknik analisis sistem bisa dilakukan menggunakan teknik state space (didasarkan pada teknik aljabar linear dari analisis nilai eigen dan vektor eigen) [5]. Selain itu penyelesaian model matematika menggunakan metode Runge-Kutta yang diselesaikan dengan bantuan software numerik,selanjutnya disimulasikan untuk mengetahui perilaku sistem secara grafik.

\section{Pembahasan}

Sebelum dilakukan analisis kestabilan sistem, terlebih dahulu ditentukan titik setimbang sistem (1)

\subsection{Titik Setimbang}

http://journal.unugiri.ac.id/index.php?journal=JaMES 
Titik setimbang sistem $E\left(J^{*}, B^{*}, F^{*}\right)$ diperoleh dengan cara

$$
\frac{d J(t)}{d t}=0, \frac{d B(t)}{d t}=0, \frac{d F(t)}{d t}=0
$$

pada sistem (1)[5]. Kondisi ini menganalogikan laju pertumbuhan suatu sistem berada pada kondisi tidak tumbuh atau steady state. Melalui substitusi (2) ke (1) diperoleh titik setimbang sistemnontrivial yaitu

$$
E\left(J^{*}, B^{*}, F^{*}\right)=E_{0}\left(J^{*}, 0, F^{*}\right)
$$

dengan $J^{*} \neq 0$, dan $F^{*} \neq 0$ dan kondisi parameter yang memenuhi kestabilan ini yaitu saat

$$
\begin{aligned}
x_{0} z_{2} & =\left(z_{0}-\frac{1}{20}\right) x_{2} \\
>\quad E\left(J^{*}, B^{*}, F^{*}\right) & =E_{1}\left(\frac{\left(-x_{1} \beta-x_{2} \alpha\right) F^{*}}{\alpha x_{0}}, \frac{\beta}{\alpha} F^{*}, F^{*}\right)
\end{aligned}
$$$$
\text { Dengan } \quad F^{*} \neq 0, \quad \alpha=\left(x_{1} y_{0} z_{3}-x_{0} y_{1} z_{3}-\right.
$$$$
\left.x_{1} y_{3}\left(z_{0}-\frac{1}{20}\right)\right) \text {, dan } \quad \beta=\left(x_{2} y_{3}\left(z_{0}-\frac{1}{20}\right)+\right.
$$$$
\left.x_{0} y_{3} z_{2}-x_{2} y_{0} z_{3}\right)
$$

Jika diperhatikan, ketiga elemen dari titik setimbang tersebut bergantung pada nilai $F^{*}$. Atau dapat diartikan bahwa titik setimbang jumlah mahasiswa dan besarnya biaya kuliah bergantung pada fasilitas yang disediakan. Dengan asumsi bahwa biaya dan jumlah mahasiswa positif maka haruslah $\alpha>0$ dan $\beta>0$ atau $\alpha<0$ dan $\beta<0$. Dua kondisi di atas berakibat $x_{0}<0$ dengan asumsi $x_{1}>0$ dan $x_{2}>0$. Kemudian saat diasumsikan $y_{0} z_{3}-y_{3}\left(z_{0}-\frac{1}{20}\right)>0$ maka ○ Untuk kondisi $\alpha>0$ dan $\beta>0$

Haruslah $y_{1} z_{3}>0$ dan $y_{3} z_{2}<0$. Misalkan saat $z_{3}>0$ dan $y_{3}>0$ maka $y_{0}>0, z_{0}>\frac{1}{20}, y_{1}>0$, dan $z_{2}<0$, berlaku juga sebaliknya.

○ Untuk kondisi $\alpha<0$ dan $\beta<0$

Haruslah $y_{1} z_{3}<0, y_{3} z_{2}>0$. Misalkan saat $z_{3}>$ 0 dan $y_{3}>0$ maka $y_{0}>0, z_{0}>\frac{1}{20}, y_{1}<0, z_{2}>0$ berlaku juga sebaliknya

\subsection{Analisis Kestabilan}

Model pada sistem (1) berbentuk no-linear, sehingga untuk melakukan analisissistem dapat dilakukan linearisasi terlebih dahulu. Dengan melakukan ekspansi deret Taylor pada sistem (1) di sekitar titik setimbang maka diperoleh matriks
Jacobian dari sistem tersebut yang ditunjukkan oleh persamaan (3).[6]

Dengan

$$
A=\left[\begin{array}{lll}
a_{11} & a_{12} & a_{13} \\
a_{21} & a_{22} & a_{23} \\
a_{31} & a_{32} & a_{33}
\end{array}\right]_{\left(J^{*}, B^{*}, F^{*}\right)}
$$

$$
\begin{aligned}
& a_{11}=x_{0} \\
& a_{12}=x_{1} \\
& a_{13}=x_{2} \\
& a_{21}=\left(-y_{1} \frac{B^{2}}{J^{2}}\right) \\
& a_{22}=\left(y_{0}+2\left(\frac{y_{1}}{J}+\frac{y_{3}}{F}\right) B\right) \\
& a_{23}=\left(-y_{3} \frac{B^{2}}{F^{2}}\right) \\
& a_{31}=\left(-z_{2} \frac{F^{2}}{J^{2}}\right) \\
& a_{32}=z_{3} \\
& a_{33}=\left(\left(z_{0}-\frac{1}{20}\right)+2 z_{2} \frac{F}{J}\right)
\end{aligned}
$$

Setelah diperoleh matriks Jacobian, selanjutnya bisa dilakukan analisis kestabilan sistem. Hal ini bertujuan untuk mengetahui perilaku sistem.[7]

\subsubsection{Analisis Kestabilan di Sekitar Titik Setimbang $E_{0}\left(J^{*}, 0, F^{*}\right)$}

Setelah dilakukan substitusi titik setimbang $E_{0}\left(J^{*}, 0, F^{*}\right)$ ke dalam matriks Jacobian A persamaan (3) diperoleh $A_{1}$, selanjutnya yaitu menentukan persamaan karakteristik yang diperoleh dengan cara

$$
\begin{gathered}
\operatorname{det}\left(A_{1}-\lambda I\right)=0 \\
\Leftrightarrow\left(y_{0}-\lambda\right)\left(\lambda^{2}-\left(x_{0}+\left(\left(z_{0}-\frac{1}{20}\right)+2 z_{2} \frac{F^{*}}{J^{*}}\right)\right) \lambda\right. \\
+x_{0}\left(\left(z_{0}-\frac{1}{20}\right)+2 z_{2} \frac{F^{*}}{J^{*}}\right) \\
\left.+x_{2} z_{2} \frac{F^{* 2}}{J^{* 2}}\right)=0
\end{gathered}
$$

Diperoleh akar-akar persamaan karakteristik atau dengan kata lain nilai eigennya yaitu

$\lambda_{1}=y_{0}$;

$\lambda_{2,3}=\frac{p \pm \sqrt{q^{2}-4 x_{2} z_{2} \frac{F^{* 2}}{J^{* 2}}}}{2}$ 


$$
\begin{aligned}
& p=\left(x_{0}+\left(\left(z_{0}-\frac{1}{20}\right)+2 z_{2} \frac{F^{*}}{J^{*}}\right)\right) ; \\
& q=\left(x_{0}-\left(\left(z_{0}-\frac{1}{20}\right)+2 z_{2} \frac{F^{*}}{J^{*}}\right)\right) ;
\end{aligned}
$$

Kestabilan disekitar titik setimbang bebas biaya dikatakan stabil asimtotik jika dan hanya jika

$\operatorname{Re}\left(\lambda_{i}\right)<0 ; \quad i=1,2,3$

$y_{0}<0$ dan

$$
\begin{gathered}
\operatorname{Re}\left(\lambda_{2,3}\right)<0 \\
\Leftrightarrow x_{0}+\left(\left(z_{0}-\frac{1}{20}\right)+2 z_{2} \frac{F^{*}}{J^{*}}\right)<0
\end{gathered}
$$

Karena $x_{0} z_{2}=\left(z_{0}-\frac{1}{20}\right) x_{2}$, maka $x_{0}\left(x_{2}+z_{2}\right)<$ 0 dan $x_{2} z_{2}<0$

Dan

$$
\begin{aligned}
& \left(x_{0}-\left(\left(z_{0}-\frac{1}{20}\right)+2 z_{2} \frac{F^{*}}{J^{*}}\right)\right)^{2}-4 x_{2} z_{2} \frac{F^{* 2}}{J^{* 2}}<0 \\
& \Leftrightarrow\left(x_{0}-\left(\left(z_{0}-\frac{1}{20}\right)+2 z_{2} \frac{F^{*}}{J^{*}}\right)\right)^{2}<4 x_{2} z_{2} \frac{F^{* 2}}{J^{* 2}}
\end{aligned}
$$

Perhatikan bahwa terdapat kondisi yang kontradiksi dimana syarat $x_{2} z_{2}<0$ tidak memenuhi untuk kondisi

$$
\left(x_{0}-\left(\left(z_{0}-\frac{1}{20}\right)+2 z_{2} \frac{F^{*}}{J^{*}}\right)\right)^{2}-4 x_{2} z_{2} \frac{F^{* 2}}{J^{* 2}}<0
$$

Sehingga dapat disimpulkan bahwa kestabilan di sekitar titik setimbang $\left(J^{*}, 0, F^{*}\right)$ dikatakan tidak stabil asimtotik.

\subsubsection{Analisis Kestabilan di Sekitar Titik Setimbang $E_{1}\left(\frac{\left(-x_{1} \beta-x_{2} \alpha\right) F^{*}}{\alpha x_{0}}, \frac{\beta}{\alpha} F^{*}, F^{*}\right)$}

Setelah dilakukan substitusi titik setimbang $E_{1}\left(\frac{\left(-x_{1} \beta-x_{2} \alpha\right) F^{*}}{\alpha x_{0}}, \frac{\beta}{\alpha} F^{*}, F^{*}\right)$ ke dalam matriks Jacobian A persamaan (3) diperoleh $A_{2}$, selanjutnya yaitu menentukan persamaan karakteristik yang diperoleh dengan cara

$$
\operatorname{det}\left(A_{2}-\lambda I\right)=0
$$

$\Leftrightarrow \lambda^{3}-\left(x_{0}+v+\varphi\right) \lambda^{2}+\left(v \varphi+z_{3} y_{3}\left(\frac{\beta}{\alpha}\right)^{2}+\right.$

$\left.x_{0}(v+\varphi)+x_{1} y_{1} w^{2}+x_{2} z_{2} \gamma^{2}\right) \lambda-$

$$
\begin{aligned}
& \left(x_{0}\left(v \varphi+z_{3} y_{3}\left(\frac{\beta}{\alpha}\right)^{2}\right)+x_{1}\left(y_{1} w^{2} \varphi+z_{2} y_{3} w^{2}\right)+\right. \\
& \left.x_{2}\left(-y_{1} z_{3} w^{2}+z_{2} \gamma^{2} v\right)\right)=0
\end{aligned}
$$

Karena persamaan karakteristiknya berbentuk polinomial derajat tiga maka sistem dikatakan stabil disekitar titik setimbang $E_{1}\left(J^{*}, B^{*}, F^{*}\right)$ jika dan hanya jika nilai bagian real nilai eigennya negative

$$
\operatorname{Re}\left(\lambda_{i}\right)<0 ; \quad i=1,2,3
$$

Bagian real dari akar-akar karakteristik bernilai negatif jika dan hanya jikasemua koefisien polinomial bernilai positif.dan semua elemen kolom sebelah kiri dari Routh array adalah positif. Hal ini sesuai dengan kriteria Kestabilan Routh.[5].Dari persamaan karakteristik diatas, maka Routh array nya yaitu

Dimana

\begin{tabular}{c|lll}
$\lambda^{3}$ & $a_{0}$ & $a_{2}$ & 0 \\
$\lambda^{2}$ & $a_{1}$ & $a_{3}$ & 0 \\
$\lambda$ & $b_{1}$ & 0 & 0 \\
$\lambda^{0}$ & $c_{1}$ & 0 & 0
\end{tabular}

$a_{0}=1$

$a_{1}=-\left(x_{0}+v+\varphi\right)$, sehingga haruslah $a_{1}>0$;

$a_{2}=\left(v \varphi+z_{3} y_{3}\left(\frac{\beta}{\alpha}\right)^{2}+x_{0}(v+\varphi)+x_{1} y_{1} w^{2}+\right.$ $\left.x_{2} z_{2} \gamma^{2}\right)$

$$
\begin{aligned}
a_{3}=-\left(x_{0}(v\right. & \left.+z_{3} y_{3}\left(\frac{\beta}{\alpha}\right)^{2}\right) \\
& +x_{1}\left(y_{1} w^{2} \varphi+z_{2} y_{3} w^{2}\right) \\
& \left.+x_{2}\left(-y_{1} z_{3} w^{2}+z_{2} \gamma^{2} v\right)\right)
\end{aligned}
$$

$b_{1}=\frac{a_{1} a_{2}-a_{0} a_{3}}{a_{1}}=\frac{a_{1} a_{2}-a_{3}}{a_{1}}$, sehingga haruslah $b_{1}>$ 0 . Karena $a_{1}>0$ maka haruslah $a_{1} a_{2}-a_{3}>0$, kondisi ini terpenuhi jika dan hanya jika $a_{2}>0$ dan $a_{3}<0$. Atau $a_{3}>0$ dengan syarat $a_{1} a_{2}>$ $a_{3} ; c_{1}=a_{3}$, sehingga haruslah $a_{3}>0$.

Sekilas dapat disimpulkan bahwa sistem stabil bersyarat. Akan tetapi pada saat $a_{1}>0$ terdapat kondisi yang kontradiksi yaitu kondisi $a_{1}>0$ terpenuhi jika dan hanya jika $y_{1}>0$ dan hal ini ternyata kontradiksi dengan pernyataan sebelumnya yang mengatakan bahwa $y_{1}<0$. 
Sehingga dapat dikatakan bahwa sistem tidak stabil di sekitar titik setimbang $E_{1}\left(\frac{\left(-x_{1} \beta-x_{2} \alpha\right) F^{*}}{\alpha x_{0}}, \frac{\beta}{\alpha} F^{*}, F^{*}\right)$.

\subsection{Simulasi dan Analisis}

Penyelesaian model (1) secara numerik dilakukan dengan menggunakan metode RungeKutta hal ini berguna untuk membentuk grafik penyelesaian dari sistem. Metode ini secara otomatis bisa diselesaikan oleh software Matlab dengan menggunakan fungsi ODE.[4]

Melalui analisis disekitar titik setimbang, maka diasumsikan nilai tiap parameter dan nilai variabel seperti yang ditunjukkan oleh Tabel 1, Tabel 2, dan Tabel 3.

Tabel 1. Asumsi Nilai Variabel

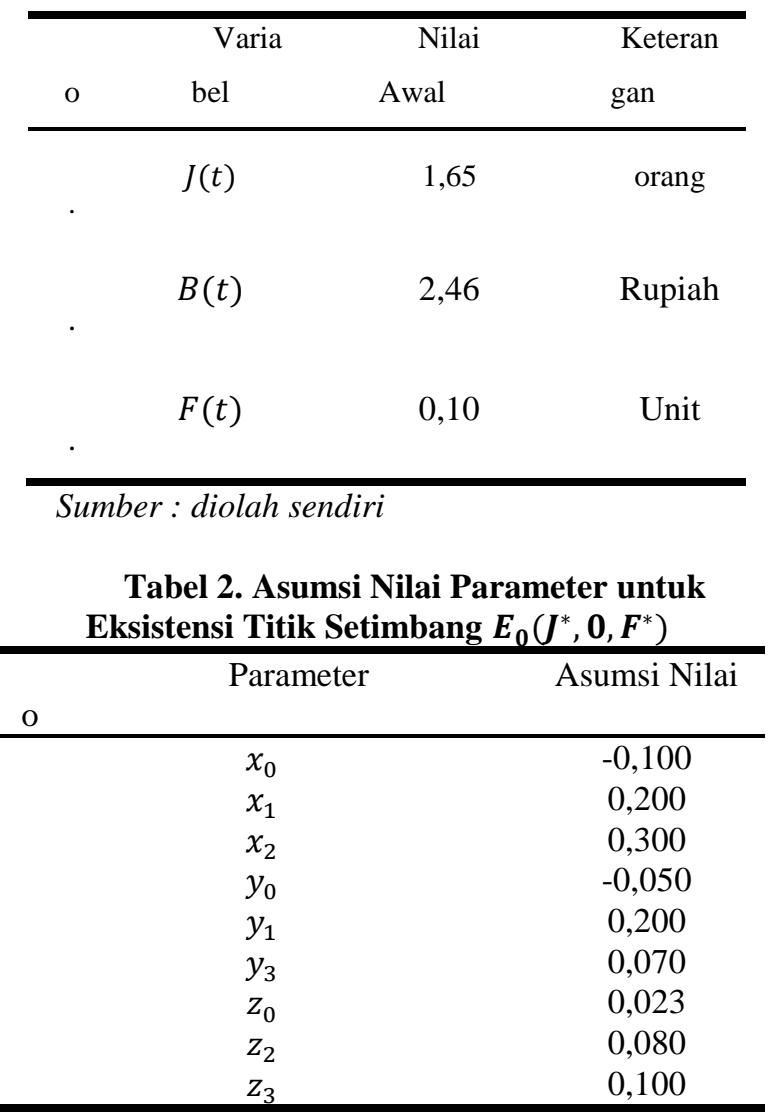

Sumber : diolah sendiri
Tabel 3. Asumsi Nilai Parameter untuk Eksistensi Titik Setimbang $E_{1}\left(\frac{\left(-x_{1} \beta-x_{2} \alpha\right) F^{*}}{\alpha x_{0}}, \frac{\beta}{\alpha} F^{*}, F^{*}\right)$

\begin{tabular}{ccc}
\hline N & Parameter & Asumsi Nilai \\
$\mathbf{0}$ & & $-0,100$ \\
\hline 1 & $x_{0}$ & 0,040 \\
2 & $x_{1}$ & 0,060 \\
3 & $x_{2}$ & 0,050 \\
4 & $y_{0}$ & $-0,100$ \\
5 & $y_{1}$ & 0,025 \\
6 & $y_{3}$ & 0,025 \\
7 & $z_{0}$ & 0,050 \\
8 & $z_{2}$ & 0,025 \\
9 & $z_{3}$ & \\
\hline
\end{tabular}

Sumber : diolah sendiri

Dengan $t$ adalah waktu (tahun). Hasil simulasi ditunjukkan oleh Gambar 2, dan Gambar 3.

Dapat dilihat pada Gambar 2 bahwa sistem tidak menuju pada suatu titik dan tidak menunjukkan adanya suatu kestabilan. Sehingga bisa dikatakan bahwa secara grafik juga menunjukkan bahwa sistem tidak stabil untuk titik setimbang $E_{0}\left(J^{*}, 0, F^{*}\right)$.

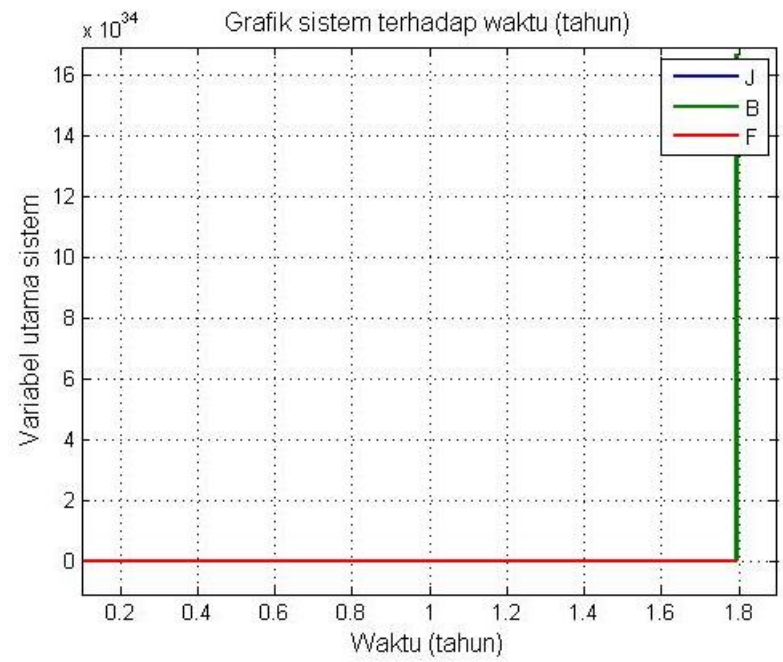

Gambar 2. Grafik sistem untuk titik setimbang

$$
\boldsymbol{E}_{\mathbf{0}}\left(\boldsymbol{J}^{*}, \mathbf{0}, \boldsymbol{F}^{*}\right)
$$

Sementara untuk simulasi dari sistem di sekitar titik setimbang

$$
\boldsymbol{E}_{1}\left(\frac{\left(-x_{1} \boldsymbol{\beta}-\boldsymbol{x}_{2} \boldsymbol{\alpha}\right) \boldsymbol{F}^{*}}{\boldsymbol{\alpha} x_{0}}, \frac{\boldsymbol{\beta}}{\boldsymbol{\alpha}} \boldsymbol{F}^{*}, \boldsymbol{F}^{*}\right) \text { ditunjukkan oleh }
$$

Gambar 3. 


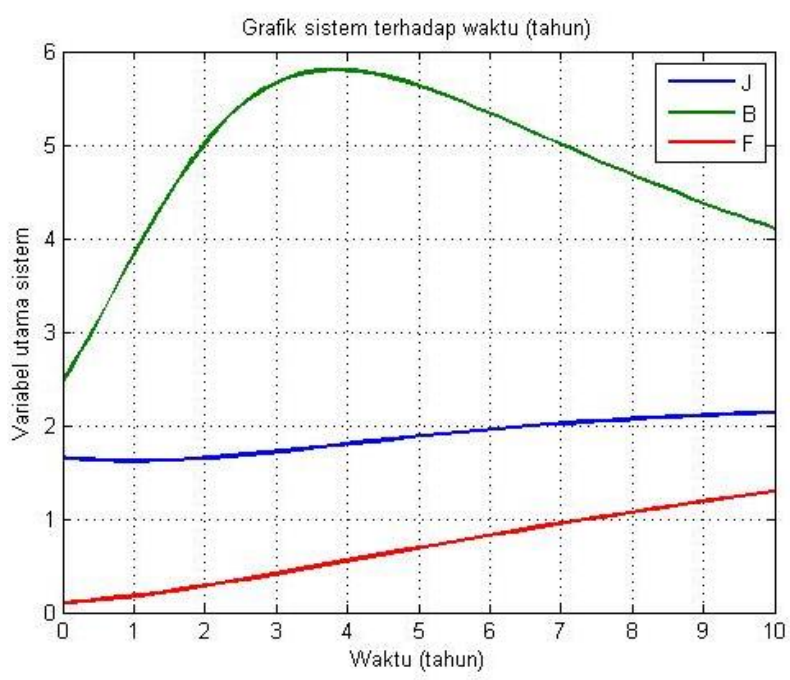

Gambar 3. Grafik sistem untuk titik setimbang $E_{1}\left(\frac{\left(-x_{1} \beta-x_{2} \alpha\right) F^{*}}{\alpha x_{0}}, \frac{\beta}{\alpha} F^{*}, F^{*}\right)$ dengan $0 \leq t \leq 10$

Grafik yang ditunjukkan oleh Gambar 3 belum menunjukkan bahwa sistem tersebut stabil di sekitar titik setimbang $\boldsymbol{E}_{\mathbf{1}}\left(\frac{\left(-\boldsymbol{x}_{1} \boldsymbol{\beta}-\boldsymbol{x}_{\mathbf{2}} \boldsymbol{\alpha}\right) \boldsymbol{F}^{*}}{\boldsymbol{\alpha \boldsymbol { x } _ { 0 }}}, \frac{\boldsymbol{\beta}}{\boldsymbol{\alpha}} \boldsymbol{F}^{*}, \boldsymbol{F}^{*}\right)$. Maka simulasi sistem di sekitar titik setimbang ini dapat ditunjukkan untuk waktu $t$ yang lebih lama. Hal ini seperti yang ditunjukkan oleh Gambar 4.

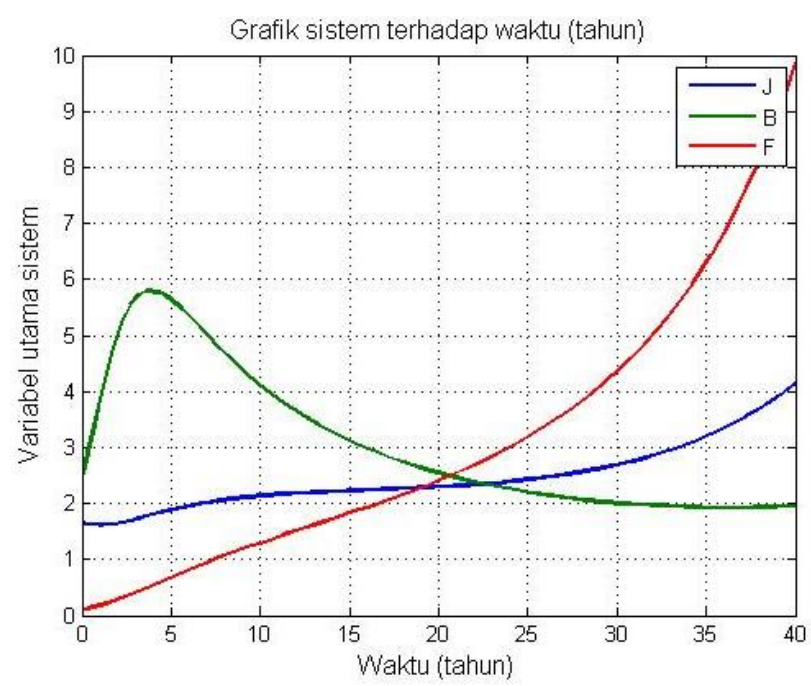

Gambar 4. Grafik sistem untuk titik setimbang $E_{1}\left(\frac{\left(-x_{1} \beta-x_{2} \alpha\right) F^{*}}{\alpha x_{0}}, \frac{\beta}{\alpha} F^{*}, F^{*}\right)$ dengan $0 \leq t \leq 40$

Dari Gambar 4 dapat dilihat bahwa sistem tidak menuju pada kondisi steady state. Sehingga dapat terlihat jelas bahwa sistem tidak stabil yang artinya sistem masih mengalami kenaikan maupun penurunan.

\section{Penutup}

Dari hasil dan pembahasan di atas dapat diambil kesimpulan bahwa sistem memiliki dua titik kesetimbangan. Setelah dilakukan analisis kestabilan disekitar titik kesetimbangan tersebut ternyata keduanya tidak stabil. Baik analisis secara analitik maupun simulasi numerik. Hal ini dapat diartikan bahwa sistem tidak bisa berada pada kondisi steady state. Dengan kata lain sistem masih akan mengalami kenaikan maupun penurunan untuk kurun waktu yang lama.

\section{Referensi}

[1] W. Ningsih and R. Khusniah, "Pemodelan Matematika pada Pertumbuhan Jumlah Mahasiswa Program Studi Pendidikan Matematika STKIP PGRI Pasuruan," presented at the KNM XIX, Universitas Brawijaya Malang, (2018).

[2] X. Guangqing and Z. Ji, "System dynamics: principles, characteristics and Recent Advances [J]," Harbin Inst. Technol. Univ., vol. 8, no. 4, (2006) 72-74.

[3] F. Ying, "The Dynamic Analysis and Mathematic Modeling for Regional Tourism System," presented at the 2014 Sixth International Conference on Measuring Technology and Mechatronics Automation (ICMTMA), (2014) 696-699.

[4] B. W. Bequette, Process Dynamic: Modeling, Analysis, and Simulation. Prentice Hall, Inc, (1998).

[5] W.E. Boyce and R.C. Di Prima, Elementary Differential Equations and Boundary Value Problems (Ninth ed.). USA: John Willey \& Sons, Inc, (2009).

[6] S. Wiggins, Introduction to Applied Nonlinear Dynamical Systems and Chaos. Berlin: Springer, (1990).

[7] W.M. Haddad and V.S. Cellaboina, Nonlinear Dynamical Systems and Control. New Jersey: Princeton University Press, (2008). 